This item was submitted to Loughborough's Research Repository by the author.

Items in Figshare are protected by copyright, with all rights reserved, unless otherwise indicated.

\title{
Teaching the multiplier: the value of a quantitative approach
}

\section{PLEASE CITE THE PUBLISHED VERSION}

http://dx.doi.org/10.1016/j.iree.2014.03.001

\section{PUBLISHER}

(c) Elsevier

\section{VERSION}

AM (Accepted Manuscript)

\section{PUBLISHER STATEMENT}

This work is made available according to the conditions of the Creative Commons Attribution-NonCommercialNoDerivatives 4.0 International (CC BY-NC-ND 4.0) licence. Full details of this licence are available at: https://creativecommons.org/licenses/by-nc-nd/4.0/

\section{LICENCE}

CC BY-NC-ND 4.0

\section{REPOSITORY RECORD}

Turner, Paul M., and Justine A. Wood. 2019. "Teaching the Multiplier: The Value of a Quantitative Approach". figshare. https://hdl.handle.net/2134/24257. 


\title{
Teaching the Multiplier: The value of a quantitative approach
}

\author{
Paul Turner and Justine A. Wood
}

\begin{abstract}
To create an engaging and motivating learning environment, we have developed software which is based on estimated parameters for the UK economy. The program allows students to both simulate the effects of economic policy on national income and its components as well as the flexibility to vary key parameters of interest in order to assess the impact on economic performance. In this paper we present the main features of the software and the model on which it is based. We discuss the potential uses of the software within a class-room context and consider two simulations. The first of these is a fiscal expansion designed to bring down unemployment and the second is an exogenous shock to consumption affecting the parameters of the consumption-income relationship. This paper advocates that students' understanding of theoretical models can be greatly enhanced by the addition of practical examples that can be used in lectures and tutorials as well as for independent study.
\end{abstract}

\section{JEL Codes: $A 20, A 22, C 88, E 12$}

\section{Introduction}

Most undergraduate macroeconomics modules begin with the Keynesian income-expenditure model. This provides a platform in which more complex models which integrate the monetary sector and the supply side can then be developed in the form of the IS-LM and AD-AS models respectively. A key part of the development of the income-expenditure model is the use of simple numerical examples in which the equilibrium level of income is determined through the multiplier process. However, these examples frequently give a highly unrealistic impression of the size of real world multipliers because they start from a stylised model of a closed economy and lump-sum taxes.

We believe that there is value in developing a realistic quantitative framework for economic models at an early stage and which allow for more realistic simulations of multiplier effects. However, there is a surprising lack of accessible software which allows students to do this. MacDonald and Turner (1989) provided the widely used package Ready-Reckoner based on the output of a number of large scale UK macroeconomic models. However, this has not been updated and is no longer easily available. More recently Fair (2004) presents a large scale macroeconometric model which is available for download from his website but this requires a level of expertise beyond that which can be reasonably expected from undergraduate students. Finally, Kapinos (2010) presents a three equation New Keynesian model which allows students to vary key parameters but his model is based on assumed rather than estimated parameter values.

In order to facilitate a more active and comprehensive learning experience for students, we have developed software which is based on estimated parameters for the UK economy. The program allows students to both simulate the effects of economic policy on national income and its components as well 
as the ability to vary key parameters of interest in order to assess the impact on economic performance. We believe this software affords students the opportunity to better appreciate how a real world economy operates compared to existing learning techniques and software packages.

Pedagogical techniques that facilitate active, engaging class-room experiences are gaining credibility, acceptance, and becoming more mainstream. Schön, (1983), Fink (2003) and Ihssen (2011) all strongly advocate active learning. Students who are highly engaged in their learning environment will have a deeper, more profound class-room experience. If there is an active learning atmosphere, it will encourage students to retain the information presented, transfer their knowledge to other unique situations, and make connections to other topics and modules. Bruner (1996) notes that by involving students and having them act as co-constructors of their learning experiences facilitates deeper comprehension, connection-building, and meaningful exercises and will reduce passive learning practise in lectures.

The software introduced in this paper has many effective applications for teaching. Practical examples presented during lecture can illustrate theoretical ideas and provide a better understanding of how different sectors of the economy work. After they have a basic foundation of how a model works, students can form groups and answer situational questions posed by the lecturer, gaining immediate feedback to assess their comprehension of the subject. Students will also benefit from having the software to practice examples while revising. Courts (1993) advocates active lecturing techniques and developing independent problem solving skills in students by promoting self-directed learners. Students are enabled to see for themselves how small changes can have large effects on the economy. Pintrich (2003) reviews actions that lecturers could take to better support students' learning. Creating learning environments that will challenge students while enabling them to have control over the task should promote enhanced learning experiences. The introduction of practical exercises with the software presented in this paper should help further accomplish both of these principles.

In this paper we set out the main features of the software and the model on which it is based. We discuss the potential uses of the software within a class-room context and consider two simulations. The first of these is a fiscal expansion designed to bring down unemployment and the second is an exogenous shock to consumption affecting the parameters of the consumption-income relationship.

\section{The Model}

At the core of our model is the Keynesian income-expenditure system. National income is defined as the sum of private sector consumption expenditures $C$, investment $I$, government consumption $G$, stockbuilding $S B$ and exports $X$ minus expenditure on imported goods $M$ :

$$
Y=C+I+G+S B+X-M
$$

In addition we assume that consumption depends on disposable income according to the relationship:

$$
C=C\left(Y^{D}\right)=C(Y-T(Y))
$$

where $T$ is net taxes out of total national income and $Y^{D}=Y-T$ defines disposable income. When estimating this relationship we first estimate the income elasticity of demand using a log-linear relationship. We then take a linear approximation around base values of consumption and disposable income such that the marginal propensity to consume is estimated as $c=\hat{\beta} \times \bar{C} / \bar{Y}^{D}$ where $\hat{\beta}$ is the estimated income elasticity and bars over variables indicate base period values. The intercept or 'autonomous consumption' is then set such that the relationship passes through the base solution values i.e. $b=\bar{C}-c \bar{Y}^{D}$. A similar procedure is adopted for the import demand function which takes the form 
$M=M(Y)$ and which allows to generate an estimate of the marginal propensity to import of the form

$m=\hat{\delta} \times \bar{M} / \bar{Y}$ where $\hat{\delta}$ is the estimated income elasticity of demand for imports. For stock-building we use a straightforward linear relationship of the form $S B=v \Delta Y$ which fits the data reasonably well.

Investment, government consumption and exports are treated as autonomous in our model.

To model the relationship between total and disposable income we disaggregate taxes into a number of sub-categories to obtain a relationship of the form:

$$
T=\sum_{i=1}^{n} T_{i}(Y)
$$

Some categories of taxation will depend on income while others are assumed to be autonomous. Those categories of taxation that depend on national income include income tax, corporation tax, value-added tax, national insurance contributions and social security transfers (which are modelled as a negative tax). Interest payments on debt and a variety of other smaller items are assumed to be autonomous. For the purposes of empirical modelling we again adopt the strategy of estimating log-linear relationships between taxes and national income and then using a linear approximation around a base solution to generate estimates of the various marginal tax rates. These should be seen as averages over the period of estimation rather than unchanging parameters. The aggregate marginal tax rate is therefore estimated as:

$$
t=\sum_{i=1}^{n} \hat{\eta}_{i} \times \frac{\overline{\bar{T}}_{i}}{\bar{Y}_{i}}
$$

where $\hat{\eta}_{i} ; i=1, \ldots . n$ are the estimated tax elasticities.

Using this approach we can generate an estimate of the textbook open-economy multiplier of the form:

$$
\frac{d Y}{d G}=\frac{1}{1-c(1-t)-v+m}
$$

The results are given in Table 1 below.

\begin{tabular}{|l|r|r|r|}
\hline & Elasticity & Marginal Effect & Intercept \\
\hline Consumption & 0.9811 & 0.9450 & 18,912 \\
\hline Taxes & 0.7859 & 0.3204 & 21,643 \\
\hline Stockbuilding & $\mathrm{NA}$ & 0.1360 & $\mathrm{NA}$ \\
\hline Imports & 1.7098 & 0.5623 & $-364,647$ \\
\hline
\end{tabular}

Table 1: Estimated parameters and linear approximations

Turning to the government sector, we estimate separate elasticities for four classes of taxation i.e. income tax, corporation tax, national insurance contributions and value added tax. We also allow for the effect of changes in GDP on the expenditure side of the government accounts through its effect on social security transfers. The results are given in Table 2 below: 


\begin{tabular}{|l|r|r|}
\hline & Elasticity & Marginal Effect \\
\hline Income Tax & 0.9458 & 0.0912 \\
\hline Corporation Tax & 1.2272 & 0.0312 \\
\hline N.I.C.S & 1.0713 & 0.0804 \\
\hline Value Added Tax & 1.5970 & 0.0775 \\
\hline Social Security & -0.9686 & -0.1176 \\
\hline
\end{tabular}

Table 2: Tax and Expenditure Elasticities and Marginal Effects

The tax system feeds back into the income-expenditure block through the effects of taxes on disposable income. We define aggregate 'taxes' as the difference between GDP and disposable income i.e.

$T=Y-Y^{D}$ and we use a linear approximation of the tax function of the form $T=t_{0}+t_{1} Y$. The marginal tax rate is determined as the sum of the marginal rates for income tax, corporation tax and NICs minus the marginal effect for social security transfers. Hence the estimated marginal rate for our model is 0.3141. We then estimate the intercept as $t_{0}=t_{1} \times T_{2011} / Y_{2011}$.

Although the core of the model comes from the short-run income-expenditure framework, we do allow for an impact effect on prices and inflation through a Phillips curve relationship. This is estimated using annual data for the period 1950-2011 and takes the form:

$$
\begin{aligned}
& \Delta \ln \left(P_{t}\right)=\underset{(0.005)}{0.0108}+\underset{(0.088)}{0.2067 \ln \left(\frac{Y_{t}}{Y_{t}^{*}}\right)+\underset{(0.075)}{0.7861} \Delta \ln \left(P_{t-1}\right)+\hat{u}_{t}} \\
& R^{2}=0.66 \quad \hat{\sigma}=0.0264 \quad D W=2.03
\end{aligned}
$$

The price level $P$ is the GDP deflator and capacity output $Y_{t}^{*}$ is measured as the deviation of the logarithm of GDP from a linear trend.

Finally, we also allow for the effects of changes in GDP on unemployment through an Okun's law relationship. This is estimated using annual data for 1972-2011 and takes the form:

$$
\begin{aligned}
& \Delta \ln \left(U_{t}\right)=\underset{(0.03)}{0.1744-6.6312 \Delta \ln \left(Y_{t}\right)+\hat{u}_{t}} \\
& \left.R^{2}=0.57 \quad \hat{\sigma}=0.93\right)
\end{aligned}
$$

where $U$ is the number unemployed in thousands. As with previous equations we use a linear approximation of the form $U=f_{0}+f_{1} Y$ around a particular observation when solving the model.

\section{Model Simulations}

In this section we discuss how the software can be used to perform model simulations. On starting the software there are two key input screens which allow the user to set values for the parameters and for the exogenous variables. The screen for the parameters is given in Figure 1. The user can set values for the marginal propensities to consume and import as well as the marginal tax rate. There is an option to automatically adjust the intercept of the relevant equation to as to maintain the linearisation around the 
base values. This is important because changes in marginal propensities can significantly affect the model solution if the intercept is not adjusted in this way. However, the user has the option of either maintaining the existing intercept values or adjusting them manually.

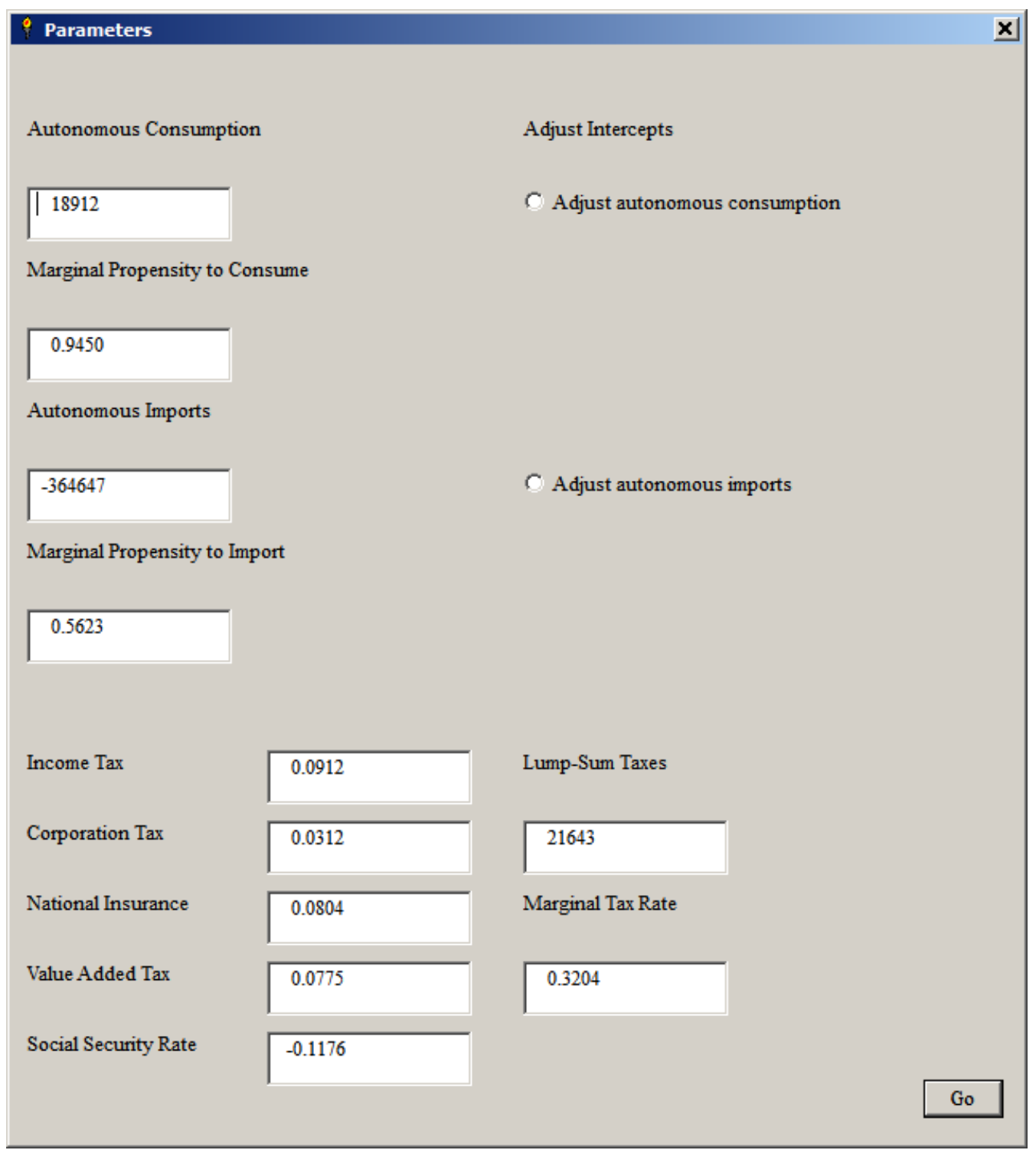

Figure 1: Setting the parameters

The next input screen allows the user to adjust the exogenous variables of the system. At present the options available consist of adjustments to government consumption, private sector investment and exports. The input screen is shown in Figure 2. 


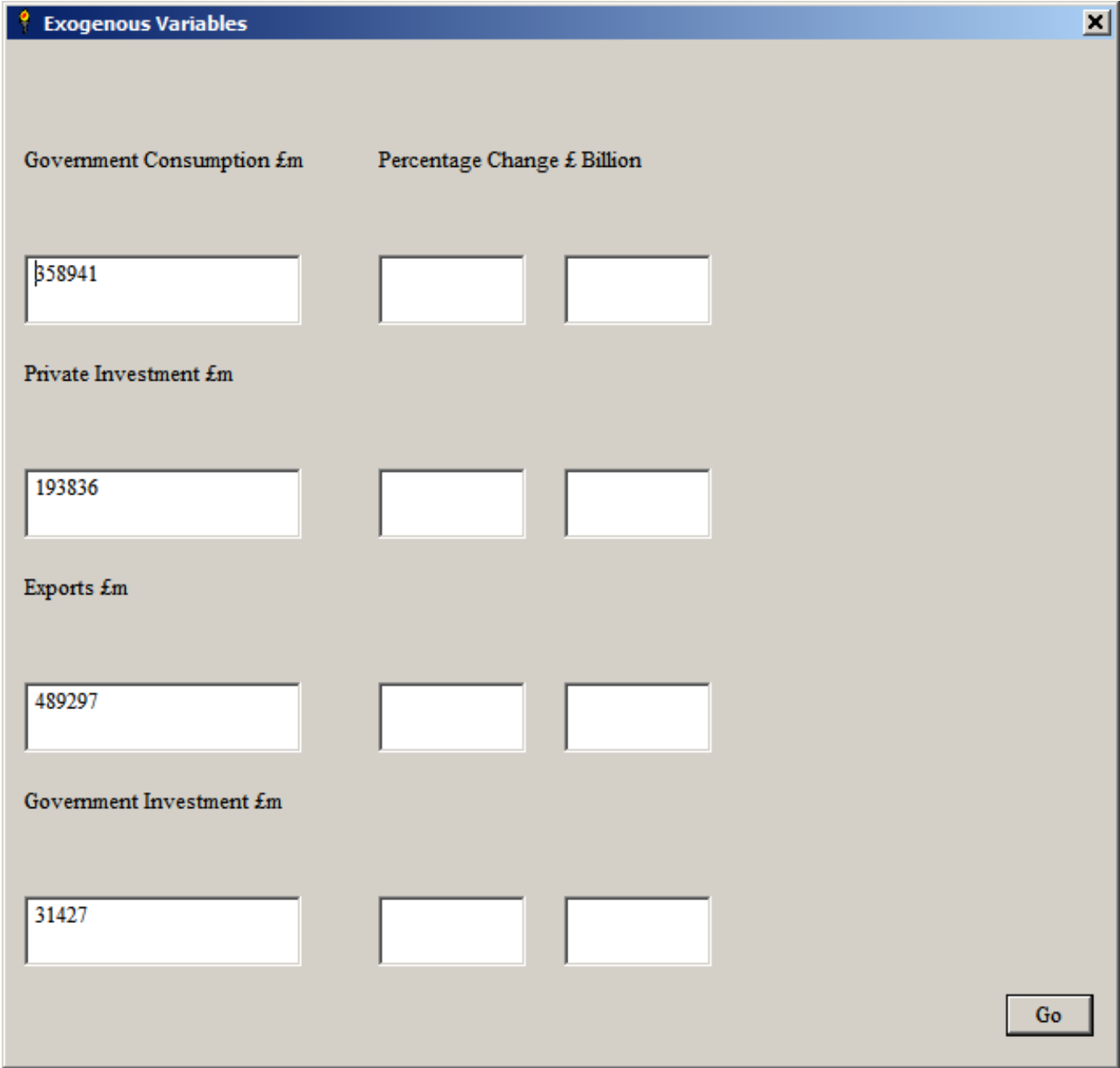

Figure 2: Exogenous variables input

As a starting point let us consider a five percent increase in government consumption expenditure. If we enter this into the screen shown in Figure 2 then we obtain the results shown in Table 3. Given our parameter estimates we obtain a value for the multiplier of 1.28. This is considerably smaller than many of the elementary textbook models which frequently use examples based on over-simplified models which yield extremely high values. For example, in a model with no overseas trade sector the multiplier formula can be written $1 /(1-c(1-t))$. If $c=0.9$ and $t=0.3$ then the multiplier becomes 2.7 . It is therefore important that we develop as complete a model as possible before we draw conclusions about the quantitative effects of fiscal policy.

Table 3 shows that the multiplier effects on different categories of expenditure depend on the relevant elasticities as well as the multiplier itself. Thus imports increase by a rather higher percentage than consumption expenditures because of the high value of the income elasticity of imports. The model also allows us to get a rough idea of the impact of a fiscal boost on unemployment and inflation with unemployment falling by 154,000 and inflation rising marginally by $0.3 \%$. 


\begin{tabular}{|l|r|r|r|r|}
\hline & Base Solution & New Solution & Change & \% Change \\
\hline GDP & 1565640 & 1588530 & 22890 & 1.46 \\
\hline Consumption & 1003948 & 1018648 & 14700 & 1.46 \\
\hline Disposable Income & 1042366 & 1057922 & 15556 & 1.49 \\
\hline Taxes & 523274 & 530608 & 7334 & 1.40 \\
\hline Imports & 515713 & 528583 & 12871 & 2.50 \\
\hline Stock Building & 3904 & 7017 & 3113 & NA \\
\hline Unemployment (000s) & 1558 & 1405 & -154 & -9.86 \\
\hline Social Security & 189252 & 186560 & -2691 & -1.42 \\
\hline Net Exports & -26416 & -39286 & -12871 & \\
\hline (\% of GDP) & -1.69 & -2.47 & -0.79 & \\
\hline Inflation & 3.09 & 3.39 & 0.30 & \\
\hline Value of Multiplier & 1.28 & 1.28 & & \\
\hline
\end{tabular}

Table 3: Effects of a 5\% increase in Government Consumption

Figures are in $\mathrm{fmn}$ at 2009 prices except where otherwise indicated

Linearised around 2012 values

Our software also permits the user to assess the effects on the government budget of changes in either the parameters of the model or the exogenous variables. Table 4 shows the detailed effects on the government budget of the same $5 \%$ increase in government consumption expenditure considered in Table 3. The breakdown of the government budget is as given in the government accounts published on the ONS website. The simulation shown in Table 4 makes clear that not all elements of the government budget are necessarily sensitive to changes in GDP. For example, interest payments are included as both a revenue and an expense for government. However, our model does not predict an effect of GDP on either of these and so the effect on the overall budgetary position is zero. In contrast, tax revenues of all kinds change when GDP changes which has obvious implications for total revenues while, on the expenditure side, social security transfers fall as GDP increases. The net effect on the government budget of a $5 \%$ increase in government consumption expenditure is therefore muted by these induced effects. In the case presented here a $5 \%$ increase in government consumption amounts to about $f 17.9 \mathrm{bn}$. The net effect on the deficit however, is for this to rise by only $f 8.8 \mathrm{bn}$ - slightly less than half of the initial increase in expenditure. 


\begin{tabular}{|l|r|r|r|r|}
\hline & Base Solution & New Solution & Change & $\%$ Change \\
\hline Income Tax & 150952 & 153040 & 2088 & 1.38 \\
\hline Corporation Tax & 39830 & 40544 & 714 & 1.79 \\
\hline National Insurance & 102622 & 104662 & 1840 & 1.79 \\
\hline VAT & 98931 & 100705 & 1774 & 1.79 \\
\hline Interest & 9505 & 9505 & 0 & 0.00 \\
\hline Other & 83262 & 83262 & 0 & 0.00 \\
\hline Total & 485101 & 491517 & 6416 & 1.32 \\
\hline Government Consumption & 358941 & 376888 & 17947 & 5.00 \\
\hline Government Investment & 31427 & 31427 & 0 & 0.00 \\
\hline Social Security & 189252 & 186560 & -2692 & -1.42 \\
\hline Debt Interest & 39016 & 39016 & 0 & 0.00 \\
\hline Total & 618636 & 633891 & 15255 & 2.47 \\
\hline Deficit & 133534 & 142374 & 8839 & \\
\hline
\end{tabular}

Table 4: Effects of a 5\% increase in Government Consumption on the Government Budget

So far we have only considered the effects of changing one of the exogenous variables of the model. However, it is also possible to conduct sensitivity analysis by changing the parameters. For example, it is often argued that the short-run marginal propensity to consume is much smaller than its long-run value. This may be because consumption depends on permanent income and temporary changes in income are not expected to persist. Therefore permanent income does not automatically rise in line with measured disposable income. Alternatively it may simply take time to adjust consumption expenditure when income rises unexpectedly. Whatever the reason, it is certainly the case that consumption functions estimated in differences usually give a rather lower income elasticity than those estimated in levels. For example, if we estimate the consumption function in differences rather than levels we obtain the following results:

$$
\begin{aligned}
& \Delta \ln \left(C_{t}\right)=\underset{(0.003)}{0.0051}+\underset{(0.089)}{0.7853} \Delta \ln \left(Y_{t}^{D}\right)+\hat{u}_{t} \\
& R^{2}=0.56 \quad \hat{\sigma}=0.0155 \quad D W=1.24 \quad t=1949 \ldots 2011
\end{aligned}
$$

This yields a short-run marginal propensity to consume of 0.7278 when linearised around the 2012 values.

To investigate the sensitivity of our model to the value of the marginal propensity to consume we will rerun the fiscal stimulus experiment of a $5 \%$ increase in government consumption but with this value substituted for the previous value. This is achieved by changing the mpc in the parameter choice screen while simultaneously allowing for an intercept adjustment to maintain the linearisation around the 2012 values. The results for the main national income categories are shown in Table 5. 


\begin{tabular}{|l|r|r|r|r|}
\hline & Base Solution & New Solution & Change & $\%$ Change \\
\hline GDP & 1565640 & 1584369 & 18729 & 1.20 \\
\hline Consumption & 1003948 & 1012714 & 8766 & 0.87 \\
\hline Disposable Income & 1042366 & 1055094 & 12728 & 1.22 \\
\hline Taxes & 523274 & 529275 & 6001 & 1.15 \\
\hline Imports & 515713 & 526244 & 10531 & 2.04 \\
\hline Stock Building & 3904 & 6451 & 2547 & NA \\
\hline Unemployment (000s) & 1558 & 1433 & -126 & -8.07 \\
\hline Social Security & 189252 & 187049 & -2203 & -1.16 \\
\hline Net Exports & -26416 & -36947 & -10531 & \\
\hline (\% of GDP) & -1.69 & -2.33 & -0.64 & \\
\hline Inflation & 3.09 & 3.34 & 0.25 & \\
\hline Value of multiplier & 1.28 & 1.07 & & \\
\hline
\end{tabular}

Table 5: Effects of a 5\% increase in Government Consumption with MPC $=0.7278$

Figures are in Emn at 2009 prices except where otherwise indicated

Linearised around 2012 values

The result of changing the MPC is, not surprisingly, to reduce the value of the multiplier significantly from 1.28 to 1.07 . Given however, that the multiplier was already quite low, the effects on the model simulation properties are quite muted. Qualitatively the direction of the effects remains the same but with somewhat lower quantitative effects. For example, unemployment falls by only 126,000 while the effects on inflation are barely noticeable in that it rises by 0.25 compared with 0.30 in the original simulation. Table 6 gives the simulation results for the government budget. Here we see that the lower value of the multiplier means that less of the effect on the deficit of the increase in government consumption is offset by higher tax revenues and lower transfers. In particular, the deficit rises by $£ 10.5 \mathrm{bn}$ compared with $£ 8.8 \mathrm{bn}$ in the previous simulation.

\begin{tabular}{|l|r|r|r|r|}
\hline & Base Solution & New Solution & Change & \% Change \\
\hline Income Tax & 150952 & 152660 & 1708 & 1.13 \\
\hline Corporation Tax & 39830 & 40414 & 584 & 1.47 \\
\hline National Insurance & 102622 & 104128 & 1506 & 1.47 \\
\hline VAT & 98931 & 100382 & 1451 & 1.47 \\
\hline Interest & 9505 & 9505 & 0 & 0.00 \\
\hline Other & 83262 & 83262 & 0 & 0.00 \\
\hline Total & 485101 & 490351 & 5250 & 1.08 \\
\hline Government Consumption & 358941 & 376888 & 17947 & 5.00 \\
\hline Government Investment & 31427 & 31427 & 0 & 0.00 \\
\hline Social Security & 189252 & 187049 & -2203 & -1.16 \\
\hline Debt Interest & 39016 & 39016 & 0 & 0.00 \\
\hline Total & 618636 & 634380 & 15744 & 2.55 \\
\hline Deficit & 133534 & 144029 & 10495 & \\
\hline
\end{tabular}

Table 6: Effects of a 5\% increase in Government Consumption on the Government Budget (MPC $=0.7278$ ) 


\section{Conclusions}

In this paper we have argued that the use of a quantitative model can add significantly to our teaching of basic concepts in macroeconomics. In particular, more realistic estimates of the multiplier can make students more aware of both the possibilities and limitations of fiscal policies such as a stimulus to deal with recession. Our argument is illustrated using simulations generated by downloadable software which permits simulation of a simple econometric model which we have estimated. We wish to emphasise that we do not put forward this model as the best available - it is simply a tractable model with plausible parameter values which we are using to illustrate a point. We see this very much as a starting point rather than an end in itself.

The software described in this paper can be downloaded from the following URL:

\section{http://www.paulecon.co.uk/MacMod1.html}

It is free for educational use but the author retains copyright. Note that, in most cases, calculations are made to the full accuracy of the computer but are then rounded to the nearest whole number. In some cases this means that totals may differ slightly from the sum of components.

\section{References}

Bruner, J. (1996) The Culture of Education, Cambridge, MA: Harvard University Press.

Courts, P. L., and Mclnerney, K. H. (1993) Assessment in Higher Education: Politics, Pedagogy, and Portfolios. Westport, Conn.: Praeger.

Fair, R. (2004) Estimating How the Macroeconomy Works, Cambridge Mass: Harvard University Press.

Fink, L. D. (2003) Creating Significant Learning Experiences: An Integrated Approach to Designing College Courses. San Francisco: Jossey-Bass.

Ihssen, B. L. (2011) Designing Courses for Significant Learning: Voices of Experience. Edited by L. Dee Fink, Arletta Knight Fink. Teaching Theology \& Religion, 14: 198 - 199.

Kapinos, P. (2010) 'A New Keynesian Workbook', International Review of Economics Education, 9(1), 111-123.

MacDonald, G and Turner, D. (1989) 'A Ready-Reckoner Package for Macroeconomics Teaching', Oxford Bulletin of Economics and Statistics, 51(2), 193-211.

Pintrich, P. R. (2003) 'A Motivational Science Perspective on the Role of Student Motivation in Learning and Teaching Contexts', Journal of Educational Psychology, 95, 667-686.

Schön, D. (1983) The reflective practitioner. London: Temple Smith. 


\section{Contact details}

Dr Paul Turner ${ }^{1}$

School of Business and Economics

Loughborough University

Loughborough

LE11 3TU

Tel: (44) 1509222722

Fax: (44) 1509223910

E-mail: p.m.turner@lboro.ac.uk

Justine Wood

School of Business and Economics

Loughborough University

Loughborough

LE11 3TU

United Kingdom

Tel: (44) 1509223622

FAX: (44) 1509223910

Email: j.a.wood@lboro.ac.uk

\footnotetext{
${ }^{1}$ Corresponding author
} 